\title{
Development and spectroscopic characteristics of the high-power wave guide He Plasma
}

\author{
Jong-Man Lee ${ }^{1}$, Sung-il Cho ${ }^{2}$, Jin-Chun Woo $^{2}$ and Yong-Nam Pak ${ }^{1, \star}$ \\ ${ }^{1}$ Department of Chemistry Education, Korea National University of Education 363-791, Korea \\ ${ }^{2}$ Division of Metrology for Quality of Life, Korea Research Institute of Standards and Science, Daejeon, Korea \\ (Received May 13, 2012; Revised August 22, 2012; Accepted August 30, 2012)
}

\section{도파관식 고출력 헬륨 플라즈마의 개발과 분광학적 특성 연구 이종만 ${ }^{1} \cdot$ 조성일 ${ }^{2} \cdot$ 우진춘 $^{2} \cdot$ 박용남 $^{1, \star}$ \\ 1한국교원대학교 화학교육과, ${ }^{2}$ 한국표준과학연구원 삶의질측정표준본부}

(2012. 5. 13. 접수, 2012. 8. 22. 수정, 2012. 8. 30. 승인)

\begin{abstract}
Okamoto cavity was modified to generate high power $(2.45 \mathrm{GHz}, 2 \mathrm{~kW}) \mathrm{He}, \mathrm{N}_{2}$ and Ar plasmas with WR-340 waveguide. Many factors which influence to the plasma generation were optimized and investigated for the spectroscopic properties of the He plasma generated. Some of the important factors are the diameter of the inner conductor, the distance between the inner and outer conductors and the distance between the tip of the inner conductor and the torch. After optimization for the He, two torches (a commercial mini torch for ICP and a tangential flow torch made locally) were compared and showed similar results for the helium plasma gas flow of $25 \mathrm{~L} / \mathrm{min} \sim 30 \mathrm{~L} / \mathrm{min}$. A tall torch (extended) was used to block the air in-flow and reduced the background intensity at $340 \mathrm{~nm}$ region (NH band). Emission intensity was measured for determination of halogen element in the aqueous solution with power and carrier gas flow rate. Electron number density and the excitation temperature were on the order of $3.67 \times 10^{11} / \mathrm{cm}^{3}$ and $4,350 \mathrm{~K}$, respectively. These values are similar or a bit smaller than other microwave plasmas. It has been possible to analyze aqueous samples. The detection limit for $\mathrm{Cl}(479.45 \mathrm{~nm})$ was obtained to be $116 \mathrm{mg} / \mathrm{L}$ and needs analytical optimization for the better performance.
\end{abstract}

요 약: 기존의 Okamoto cavity를 변형시킨 WR-340 도파관을 사용한 cavity를 제작하고 고출력 $(2.45 \mathrm{GHz}$, $2 \mathrm{~kW}$ )의 헬륨, 질소 및 아르곤 마이크로파 플라즈마(MIP; Microwave Induced Plasma)를 성공적으로 형 성시켰다. 플라즈마 생성의 주요한 요인들은 내부전도체의 직경과 내부전도체와 외부전도체간의 간격, 내부전도체 끝과 토치의 위치 등이 있으며 그 중 헬륨 마이크로파 플라즈마에 대하여 cavity의 디자인을 최적화시키고 그 특성을 조사하였다. ICP(Inductively Coupled Plasma)용 mini 토치와 자체 제작한 나선 형흐름토치를 비교 연구한 결과, 헬륨 플라즈마 기체 흐름량은 약 $25 \mathrm{~L} / \mathrm{min} 30 \mathrm{~L} / \mathrm{min}$ 로서 서로 비슷하 였다. 토치 상단부에 석영관을 덧쓰워 공기유입을 막은 결과, $340 \mathrm{~nm}$ 근처의 NH분자선들이 없어지거나 감소하였다. 플라즈마의 온도 및 전자밀도를 측정한 결과, $4,350 \mathrm{~K}$ 의 들뜸 온도와 $3.67 \times 10^{11} / \mathrm{cm}^{3}$ 의 전자

Corresponding author

Phone : +82-(0)43-230-3732 Fax : +82-(0)43-232-7176

E-mail : pakyn@knue.ac.kr 
밀도를 얻었다. 이 값들은 기존의 다른 마이크로파 플라즈마와 비슷하거나 약간 작은 값이다. 고출력의 플라즈마로서 수용액을 직접 분석하는 것이 가능하였고 현재 $\mathrm{Cl}$ 의 검출한계는 $116 \mathrm{mg} / \mathrm{L}$ 수준으로서 아 직 분석적인 최적화가 필요한 단계이다.

Key words: High power microwave plasma, MIP, Okamoto cavity, Helium plasma, WR-340 waveguide

\section{1. 서 론}

할로겐 원소들은 높은 여기 에너지를 갖고 있기 때 문에 다른 원소들에 비해서 원자분광 분석법의 적용 이 쉽지 않다. 이에 따라 높은 에너지를 가진 헬륨 플 라즈마, 그 중에서도 마이크로파 플라즈마의 개발에 최근까지도 여러 학자들이 관심을 가져왔다. 마이크로 파 플라즈마(Microwave plasmas)는 유도결합 플라즈 마(ICP; Inductively Coupled Plasma)와는 달리 아르곤 이외의 여러 플라즈마 기체를 사용하여 플라즈마를 생성할 수 있는 이점이 있다. 특히 헬륨 플라즈마를 생성할 수 있는데 헬륨은 높은 여기에너지를 가지고 있어서 여기하기가 쉽지 않은 여러 비금속원소에 대 하여 효과적인 분석을 할 수 있다. 또한 마이크로파 플라즈마의 경우에는 기체의 소비량이 적고, 장치도 간단하여 여러 연구들이 진행되어 왔는데 현재까지 개발된 마이크로파 플라즈마의 형태들을 살펴보면 공 명관을 사용한 Beenakker의 $\mathrm{TM}_{010}$ 형태의 cavity, ${ }^{1-3}$ 표 면파를 이용한 surfatron, ${ }^{4-5}$ 동축 형태의 관을 사용하 여 끝에서 플라즈마가 발생하는 MPT (microwave plasma torch), ${ }^{6-7}$ SWP (surface wave plasma) ${ }^{8-9}$ 그리고 CCMP (capacitively coupled microwave plasma) ${ }^{10-11}$ 등 이 있다. 하지만 이들은 주로 동축케이블(co-axial cable)을 사용하기 때문에 고출력의 마이크로파 사용에 제한을 주고 있으며 주로 $500 \mathrm{~W}$ 이하의 플라즈마를 생 성하는데 유리하다. 최근까지도 Hoskinson ${ }^{12}$ 등은 MSSR (microstrip split ring resonator)이라고 하는 새로운 형태 의 낮은 출력 마이크로파 플라즈마를 개발하고 기체크 로마토그래피의 검출기로 사용하였다. Jankowski ${ }^{13-15}$ 등은 삼상의 회전장(three phase rotating field)을 사용하 는 $30 \mathrm{~W}-150 \mathrm{~W}$ 급의 마이크로파 플라즈마를 개발하고 $\mathrm{ICP}$ 와 같은 형태인 삼각형 링 형태의 플라즈마를 생성 시켰고 이를 바탕으로 고체 시료와 액체시료 등에 대 하여도 적용이 가능함을 보여주었다.

하지만 마이크로파 플라즈마는 시료에 대하여 loading 현상을 보여주며 불안정하거나 심하면 꺼지기
도 한다. 따라서 대부분의 분석시료가 수용액임을 고 려할 때에 액체 시료를 직접 분석할 수 있는 충분한 출 력을 가진 마이크로파 플라즈마의 개발이 필요하다. 이 에 따라 수 년 전부터 수용액시료의 직접 도입이 가능 한 고출력 $\left(\mathrm{kW}\right.$ 이상)을 사용할 수 있도록 도파관 ${ }^{16-24}$ (wave guide)을 이용하려는 연구가 계속되고 있다. Carnahan의 연구팀 ${ }^{25-26}$ 은 Beenakker cavity에 도파관을 이용한 kip-MIP (kilowatt-plus helium microwaveinduced plasma)를 개발 - 연구하였다. Okamoto 등은 도파관 (WR-430)을 이용하여 대기압 조건에서 $\mathrm{He},{ }^{16} \mathrm{~N}_{2}{ }^{18-23}$ 또는 혼합기체 ${ }^{24}$ 를 플라즈마 기체로 사용하여 annular 모양의 안정한 플라즈마를 생성하고 이 들을 분석에 이용하고 있다. $1.5 \mathrm{~kW}$ 정도의 높은 출력을 이용할 수 있고 에너지 전달방식 면에서 표면파 방식(surface wave mode)을 이용한 것으로 Okamoto cavity 라고 불리고 있으며 방출분광법뿐 아니라 질량 분석법에까 지 적용하고 있다.

본 연구는 도파관을 이용하는 Okamoto cavity를 근 간으로 하여 도파관의 크기가 축소 변형된 WR-340 type을 사용하고 그에 따른 cavity를 제작하여 고출력 의 헬륨 및 여러 기체를 사용한 마이크로파 플라즈마 를 생성하고자 하였다. 본 연구에서 개발한 cavity와 기존의 Okamoto cavity와 가장 기본적인 차이점은 도 파관과 cavity의 크기를 줄여서 좀 더 작지만 더 효율 적인 플라즈마를 만드는 것이다. 특히 Okamoto가 개 발하지 못한 분석용 고출력 헬륨 플라즈마를 개발하 고 특징을 연구하는데 그 목적이 있다. 또한 플라즈마 기체흐름의 효율성을 높이기 위하여 토치를 개발하여 낮은 플라즈마 기체흐름에도 안정된 플라즈마를 생성 하고자 하였다. 생성된 플라즈마의 성격을 알아보기 위하여 열역학적 온도와 전자밀도들을 구하여 본질적 인 면을 더 이해하고자 하였으며 우선 일차적으로 안 정한 고출력 헬륨 플라즈마 개발과 그 열역학적 기본 적인 성질을 조사하는데 초점을 두었다. 헬륨 플라즈 마의 실제적인 분석능력과 응용은 곧 이은 후속연구 에서 다루고자 한다. 
Table 1. The differences between Okamoto cavity and the one developed in this experiment

\begin{tabular}{|c|c|c|c|}
\hline & & Okamoto cavity & Cavity \\
\hline \multirow{3}{*}{ Waveguide-type } & Type & WR-430 & WR-340 \\
\hline & Height(inner) & $54.6 \mathrm{~mm}$ & $43.2 \mathrm{~mm}$ \\
\hline & Width(inner) & $109.2 \mathrm{~mm}$ & $86.4 \mathrm{~mm}$ \\
\hline \multicolumn{2}{|c|}{ Discharge tube } & Double concentric & Triple concentric \\
\hline \multirow{3}{*}{ Cavity } & ght & $6 \mathrm{~mm}$ & $6.4 \mathrm{~mm}$ \\
\hline & ductor(i.d) & $\Phi 40 \mathrm{~mm}$ & Ф $36 \mathrm{~mm}$ \\
\hline & ductor(i.d) & $\Phi 16$ mm & $\Phi 14.8 \mathrm{~mm}$ \\
\hline
\end{tabular}

\section{2. 실 험}

본 실험 장치는 WR-340 type의 도파관을 이용하여 annular 모양의 플라즈마를 발생시킨다. 본 시스템의 특 징을 Okamoto cavity와 비교하여 보면 Table 1에 나타 나 있는 것처럼, 먼저 도파관과 공명관의 크기를 줄여 소형화하였고 방전튜브를 ICP용 작은 토치와 low-gas flow 토치를 사용하였다는 점이다. 전반적인 장치를 마 이크로파 시스템, cavity 및 토오치, 시료도입장치, 광학 부로 나누어 살펴보면 다음과 같다.

\section{1. 마이크로파 플라즈마 시스템}

장치의 전반적인 개략도는 Fig. 1에, 장비의 제원 은 Table 2에 나타내었다. 먼저 마이크로파 발생장 치인 출력장치에서 마이크로파가 발생되어 도파관 을 따라 cavity에 전 달된다. 순환장치(circulator)는 load된 일정 파장의 마이크로파(forward power)를 진행시키지만 되돌아오는 반사파(reflected power)는 열로 전환시켜 마이크로파 발생장치를 보호하는 역 할을 한다. Directional coupler는 출력계가 연결되 어 있어서 도파관을 지나는 입력파와 반사파의 크 기를 알려준다. Three stub tuner는 마이크로파가 cavity의 중심에 집중되도록 적절한 튜닝(tuning)이 가능하며, tapered waveguide는 도파관의 높이(h)를 $43.2 \mathrm{~mm}$ 에서 $6.4 \mathrm{~mm}$ 로 줄여 cavity에 연결되도록 하였다.

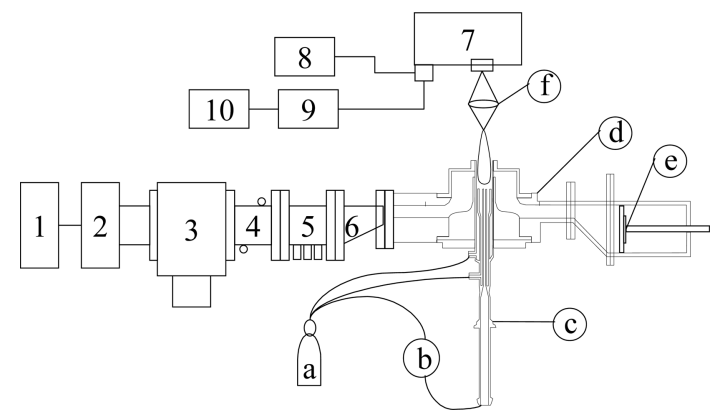

Fig. 1. Schematic diagram of the MIP system used in this experiment. [1: microwave power supply, 2 : microwave generator, 3: circulator, 4: directional coupler, 5: threestub tuner, 6: tapered waveguide, 7: monochromator, 8: high-voltage power supply, 9: computer, 10: printer, a: He-gas, b:nebulizer, c: discharge tube, d: cavity, e: plunger, f: lens and skimmer]

\subsection{Cavity와 torch}

Cavity의 단면도는 Fig. 2에서 나타내었다. 대부분의 재질은 brass로 제작되었고 내부전도체(inner conductor) 와 외부전도체(outer conductor)는 beryllium-copper로 제작되었다. 점화는 고압점화장치로 아르곤 기체를 점 화시켜 플라즈마를 형성한 다음 기체 전환을 통해 질 소와 헬륨의 플라즈마를 형성할 수 있다. 아르곤 플라 즈마가 형성되면 $50 \mathrm{~W}$ 정도의 반사파가 존재하지만 헬륨 플라즈마로 전환되면 반사파는 거의 영의 값을 갖는다. Okamoto cavity와 비교해 보면 본 연구에서 사용된 자체 제작한 cavity는 전체적으로 조금 소형이

Table 2. Experimental apparatus used in the experiment

\begin{tabular}{lll}
\hline \hline & \multicolumn{1}{c}{ Specification } & \multicolumn{1}{c}{ Model } \\
\hline Power supply & $0 \sim 2.0 \mathrm{~kW}$ & SM745 Power Supply \\
Generator & $2.45 \mathrm{GHz}$ & UWHEAD 2.0WC-SM \\
Circulator & Water cooled style & Industrial Isolator 2722 162 10311 \\
Directional coupler & Power meter attached & SAIREM S.A \\
Monochromator & Czerny-Turner 2400 groove/mm & Spex 1000 \\
\hline
\end{tabular}




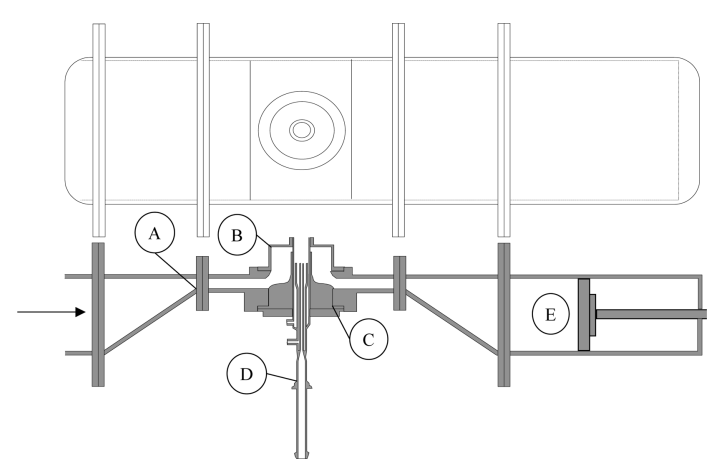

Fig. 2. Cross section of cavity used in the experiment. [A: tapered waveguide, B: outer conductor, $\mathrm{C}$ : inner conductor, D: discharge tube, E: plunger]

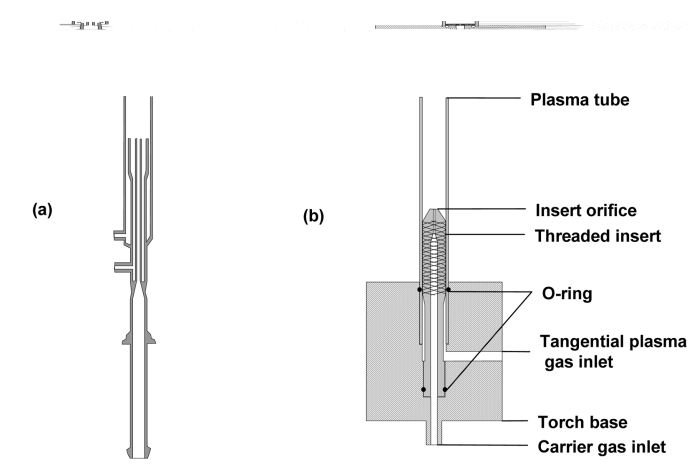

(a) ICP small torch(three concentric) (b) low-gas-flow torch(two concentric)

Fig. 3. Schematic diagram of two torches used in the experiment. a) is a commercial ICP small torch b) is manufactured in the lab.

며 높이는 약간 크다.

토치는 먼저 $\mathrm{ICP}$ 용 작은 토치를 먼저 사용하였으며, 또한 기체 사용량을 줄이는 목적으로 low-gas flow 토 치를 제작하여 사용하였다. Fig. 3의 좌측에 있는 ICP 용 작은 토치는 한 세트로 되어 있고 열에 강한 석영 관(GE Type 214 Quartz Tubing)으로 구성이 되어 있 다. 최외곽부 $(\mathrm{o} . \mathrm{d}=\Phi 12.7 \mathrm{~mm}, \mathrm{i} . \mathrm{d}=\Phi 10.5 \mathrm{~mm})$ 를 통 하여 플라즈마 기체 $\left(\mathrm{F}_{\mathrm{p}}\right)$ 가 플라즈마를 생성하는 데 사 용이 되며 중간관(o.d=Ф $9.5 \mathrm{~mm}, \mathrm{i} . \mathrm{d}=\Phi 7.5 \mathrm{~mm})$ 은 플라즈마가 토치에 닿는 것을 방지한다. 중심관(o.d= $2.0 \mathrm{~mm}, \mathrm{i} . \mathrm{d}=0.6 \mathrm{~mm}$ )을 통해 시료가 운반기체에 의해 플라즈마로 도입된다. 또한, 본 실험실에서 제작한 low-gas flow 토치 ${ }^{27}$ 는 Fig. 3에 나타내었다. 이 토치 는 크게 세 부분으로 나뉘어 구성되어 있으며 본지 지체(base; Teflon), 나사식으로 가공된 삽입세라믹 (machinable ceramic; Corning Glass Works, Corning, N.Y.), 석영관(o.d=Ф $12.7 \mathrm{~mm}, \mathrm{i} . \mathrm{d}=\Phi 10.5 \mathrm{~mm})$ 으로

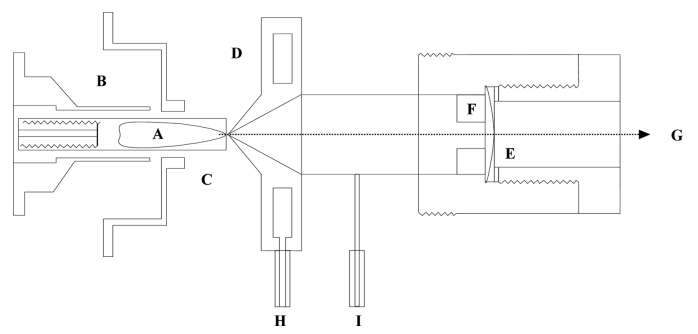

Fig. 4. Schematic diagram of the interface system [A: MIP, B: cavity, C: torch, D: cool block, E: lens, F: masking plate, G: direction to monochromator, $\mathrm{H}$ : water cooling, I: cut-off gas inlet]

구성되어 있다. 이 토치의 특징은 무엇보다 플라즈마 기체의 나선형 흐름을 유도하기 위해서 세라믹 insert 를 사용하는 것이다. 플라즈마 기체는 접선방향으로 도입되어 시계방향으로 파인 나선형 홈을 따라 흐른 다. 내부 ceramic은 4선 식으로 V-모양의 홈이 파이며 $1.54 \mathrm{pitch} / \mathrm{cm}$ 와 $1.17 \mathrm{~mm}$ 의 너비, $0.45 \mathrm{~mm}$ 의 깊이로 제작되었다. 시료가 도입되는 중심관은 $\Phi 0.7 \mathrm{~mm}$ 크 기로 제작하였다.

\section{3. 광학부}

플라즈마는 수평형 관측(end-on observation) $)^{28}$ 이 더 큰 감도를 줄 수 있으므로 측면형(side-on view)보다 는 수평형 관측을 사용하였다. 광학적 관측을 위한 연 결을 Fig. 4에 나타내었다. 먼저 ICPMS에서 사용하는 스키머(skimmer) 형태의 작은 구멍 $(3.0 \mathrm{~mm})$ 을 사용 하여 플라즈마의 외곽의 관찰을 피하고 시료가 통과 하는 중심부를 측정하여 신호 대 바탕비를 향상시켰 다. 또한, 플라즈마의 꼬리 지역에서 불안전한 재결 합반응 영역(recombination reaction zone)의 형성을 제거하고, 외부로부터의 공기의 유입을 방지하기 위 하여 $1 \mathrm{~L} / \mathrm{min}$ 의 차단기체를 흘려주었다. 그리고 플 라즈마 들뜸 광원이 고온이므로 광학부는 열에 의해 손상을 받을 수 있기 때문에 수냉으로 스키머와 차 단기체를 포함한 연결 장치를 보호하였으며, 렌즈 $(\mathrm{f}=80 \mathrm{~mm})$ 를 사용하여 측정원소의 방출광을 입구슬 릿에 집광시켰다. 다음 Table 3 에 ICP용 작은 토치 를 사용하여 형성되는 플라즈마를 사용할 때의 일반 적인 실험 조건을 실었다.

\section{3. 결과 및 고찰}

\section{1. 플라즈마의 형성과 최적화}

먼저 본 장치로 여러 기체에 대한 플라즈마를 형성 
Table 3. Operating conditions for the high power helium MIP of the modified Okamoto cavity

\begin{tabular}{clc}
\hline \hline & & Range \\
\hline Generator & Power, W & $600-1,000$ \\
\hline \multirow{4}{*}{ Torch } & Coolant gas, L/min & 25.0 \\
& Auxiliary gas, L/min & 3.0 \\
& Carrier gas, L/min & 1.0 \\
& Cut-off gas, L/min & 1.0 \\
\hline \multirow{2}{*}{ Nebulizer } & L/min & 1.0 \\
\hline
\end{tabular}

하고 그 특징들을 간단히 살펴보았다. $\mathrm{Ar}$ 플라즈마는 출력과 기체의 유량에 별 관계없이 쉽게 점화가 이루 어진다. $400 \mathrm{~W}$ 에서 아르곤을 $3 \mathrm{~L} / \mathrm{min} 5 \mathrm{~L} / \mathrm{min}$ 을 흘 려주며 점화시키면 쉽게 아르곤 플라즈마가 형성이 되며 Fig. 5에서 보는 것과 같이 플라즈마는 토치의 벽 쪽으로 근접하여 형성된다. 그러나 현재 이 플라즈 마는 안정한 annular 형태가 아니어서 방전튜브가 상 할 우려가 있으므로 곧 질소나 헬륨으로 기체 전환을 해 주어야 한다. 본 연구에서는 헬륨에 집중하였으므 로 $\mathrm{Ar}$ 플라즈마는 아직 분석적으로 이용 가능할 정도 로 충분히 연구된 상태가 아니다. 추후의 연구를 통하 여 최적조건을 찾아내면 충분히 실용이 가능한 플라 즈마로 생각된다.

질소 플라즈마는 분홍색 플라즈마로 지름이 $\Phi 6$ $\mathrm{mm} \Phi 7 \mathrm{~mm}$ 정도이고 운반기체에 의해 쉽게 도넛형 태의 플라즈마가 생성되므로 분석에 용이할 것으로 보인다. 질소 플라즈마는 $\mathrm{Ar} \mathrm{ICP}$ 와는 다른 바탕을 보 여주며 특히, 질량분석법에서는 $\mathrm{Ar}$ 의 화학종에 의한 간섭이 없으므로 현재 ICPMS에서 사용되고 있다. 헬 륨 플라즈마는 본 연구의 분석에 사용된 연 파란색 플라즈마로 지름이 $\Phi 7 \mathrm{~mm} \Phi 9 \mathrm{~mm}$ 정도의 플라즈 마를 형성하였다. 출력이 증가할수록 플라즈마의 지름 은 증가되고 운반기체에 의해 플라즈마의 중심부로 시료를 도입할 수 있다. 본 연구에서는 헬륨 플라즈마
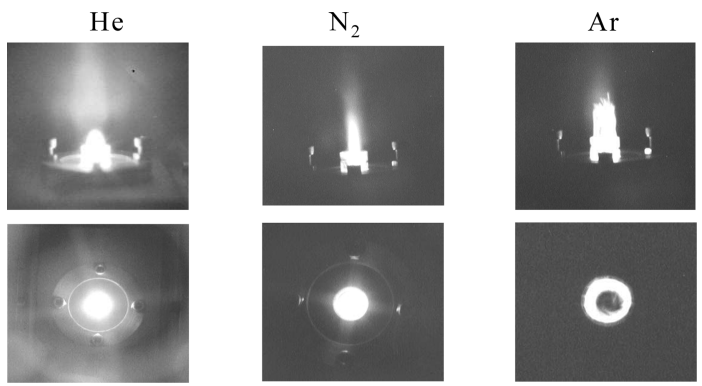

Fig. 5. The shapes of $\mathrm{He}, \mathrm{N}_{2}$, Ar plasmas observed.
의 형성 조건을 최적화 하고자 하였으며 그 과정은 다음과 같다. 즉, 플라즈마 형성에 영향을 미치는 요 인들은 $\mathrm{g}$ 값(내부전도체와 외부전도체의 끝판인 endplate와의 간격), $\mathrm{x}$ 값(내부전도체의 끝 과 토치의 중 심관끝과의 거리), end-plate의 지름인 $\mathrm{D}$, 내부전도체 의 직경 $(r)$, 플라즈마 및 시료운반기체 흐름량들이 있 으며 이 들을 변화시켜 가면서 플라즈마의 모습을 관 찰하였다. 최적 상태를 찾은 뒤 시료를 플라즈마에 도 입하고 출력을 $400 \mathrm{~W} 900 \mathrm{~W}$ 까지 변화시키면서 신호 의 세기를 관찰하였다.

내부전도체와 외부전도체 간의 간격 $\mathrm{g}$ 값은 매우 중 요한 요인인데 $4 \mathrm{~mm} 20 \mathrm{~mm}$ 까지 변환시키며 플라 즈마를 형성하였다. 최적치는 플라즈마의 크기를 고려 하여 볼 때, $7 \mathrm{~mm}$ 가 가장 좋은 모습을 보여 주었다.

내부 전도체 끝과 토치의 중심관 끝 사이의 거리 $\mathrm{x}$ 를 조사해본 결과 $3 \mathrm{~mm} 20 \mathrm{~mm}$ 까지 플라즈마 생성 이 가능하였다. 플라즈마는 내부 전도체와 외부 전도 체 사이에서 형성되어 플라즈마의 기체흐름에 의해 약간 외부로 치우쳐 형성되지만 내부로도 침투가 가 능하므로 토치가 너무 cavity 안으로 들어가지 않아야 한다. ICP용 작은 토치를 사용할 때는 $7 \mathrm{~mm}$ 근처에 서 사용 가능하지만 보조기체를 사용하지 않으면 $\mathrm{Si}$ 스펙트럼인 $261.6 \mathrm{~nm}$ 에서 스펙트럼이 관찰된다. 실제 가시적으로 토치가 노랗게 변화되는 것과 튜브의 손 상을 관찰 할 수 있었다. 세라믹(machinable ceramic) 으로 만든 low-gas flow 토치는 $18 \mathrm{~mm}$ 에서 실험하였 으나 토치는 상하지 않았고 $\mathrm{Al} 396.2 \mathrm{~nm}$ 에서 어떤 방 출도 관찰되지 않음을 보아 안전함을 알 수 있었다. 하지만 그 이하에서는 세라믹 insert가 가열됨이 관찰 되었다. 최적치는 $\mathrm{ICP}$ 용 작은 토치의 경우, $\mathrm{x}$ 값을 7 $\mathrm{mm}$ 로, low-gas flow 튜브는 $18 \mathrm{~mm}$ 로 하여 실험에 사 용하였다.

End-plate는 두께 $0.5 \mathrm{~mm}$ 의 얇은 구리판으로 플라 즈마의 길이에 영향을 주는 인자이다. 직경 $\mathrm{D}$ 값을 $\Phi$ $12.7 \mathrm{~mm}, \Phi 13.3 \mathrm{~mm}, \Phi 19.0 \mathrm{~mm}$ 를 각각 사용하여 플라즈마를 관찰한 결과 지름이 증가할수록 모든 출 력에서 플라즈마의 길이는 길어진다. 이는 end-plate를 통해 앞쪽으로 마이크로파가 전달되면서 나오기 때문 이라고 생각된다. 플라즈마의 길이를 측정할 때 gap 사이의 플라즈마의 길이는 고려하지 않았다.

외부 전도체를 제거해도 플라즈마는 형성이 될 수 는 있지만(400 W에서 $4.5 \mathrm{~cm}$ 정도의 길이) 마이크로 파의 누출이 심하여 $\left(10 \mathrm{~mW} / \mathrm{cm}^{3}\right)$ 사용할 수 없었다. 기 체의 사용량은 외부 전도체(end-plate)의 내부직경 크

Vol. 25, No. 5, 2012 
기에 따라 다르며 직경의 크기가 클수록 플라즈마가 밖으로 돌출 되면서 가늘어지기 때문에 적게 사용될 수 있다. 본 연구에서는 $\Phi 13.3 \mathrm{~mm}$ 에서 좋은 안정성 을 보여주었으므로 이것을 선택하여 사용하였다.

내부전도체의 직경을 $\Phi 14.8 \mathrm{~mm}, \Phi 16.8 \mathrm{~mm}, \Phi$ $18.8 \mathrm{~mm}$ 로 변환시켜가면서 플라즈마의 형태를 관찰 하였을 때 플라즈마의 크기는 전도체의 직경에 따라 각각 $\Phi 3 \mathrm{~mm}, \Phi 4 \mathrm{~mm}, \Phi 5 \mathrm{~mm}$ 로 증가하였다. 플 라즈마가 너무 크면 밀도가 낮으므로 전도체의 직경 은 $\Phi 16.8 \mathrm{~mm}$ 를 최적치로 선택하였다.

이상과 같이 안정한 고출력 헬륨 플라즈마의 생성 에 미치는 여러 요인들을 살펴보고 최적화 하였는데 또 다른 하나의 중요한 요인은 토치일 것이다. 본 연 구에서는 상업용인 $\mathrm{ICP}$ 용 작은 토치와 자체 제작한 low-gas-flow 토치 등 간단히 2 개의 토치에 대한 비 교를 실행하였다. 먼저 $\mathrm{ICP}$ 용 작은 토치(3 중관식)로 실험을 하여본 결과, 분 당 $25 \mathrm{~L}-30 \mathrm{~L}$ 정도의 헬름 기체가 소비되었고 좀 더 효율적인 기체흐름을 위해 low-gas flow 토치를 제작 사용하였으나 아직까지 기 체 흐름량은 크게 개선되지 않았다. 이것은 토치 내부 의 튜브 끝 부분(end-plate 으로부터 $2 \mathrm{~cm} 3 \mathrm{~cm}$ 근처) 에 많은 열을 받아 튜브가 가열되고 이를 냉각시키기 위해 많은 기체 흐름량이 요구되는 것으로 생각된다. 현재는 low-gas-flow 토치에서 홈은 4중 나선으로 제 작하였으나 더 효율적인 나선형 흐름을 위하여서 향 후에는 현재의 $1.54 \mathrm{pitch} / \mathrm{cm}$ 보다 더 조밀한 pitch를 사용하여야 할 것으로 생각된다.

플라즈마에 의해 형성된 전반적인 스펙트럼을 200 $\mathrm{nm} 500 \mathrm{~nm}$ 에 걸쳐서 분광선들을 관찰하였다. 바탕 스펙트럼을 조사한 결과, Fig. 6과 같이 매우 복잡하 게 나타났다. 이 들은 $\mathrm{OH}$ 와 $\mathrm{NH}$ 같은 분자들의 분자 선들로 외부공기의 유입이나 접촉으로 보인다. 외부로 부터 공기가 유입되는 것을 줄이기 위해 토치 상부에 석영관 $(\mathrm{o} . \mathrm{d}=\Phi 21.6 \mathrm{~mm}, \mathrm{i} . \mathrm{d}=\Phi 18.2 \mathrm{~mm})$ 을 덧 붙여

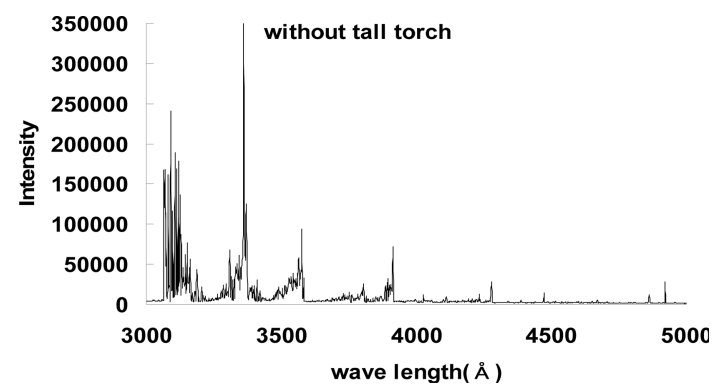

Fig. 6. Molecular band shown in He MIP without a tall torch.

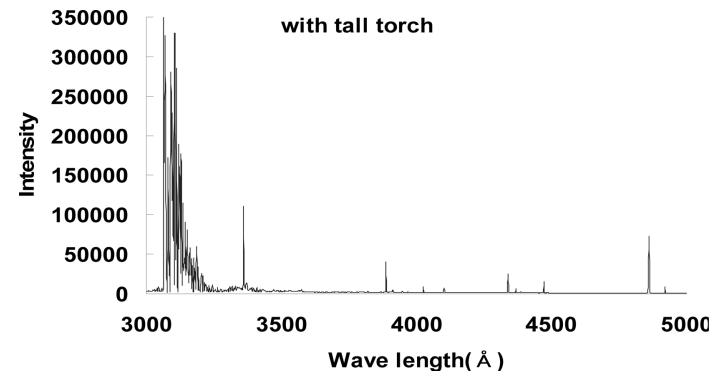

Fig. 7. Molecular band of He MIP with a tall torch.

사용하여 외부 공기와 플라즈마의 접촉을 피할 수 있 도록 한 결과 Fig. 7에서와 같이 전반적인 바탕선이 낮아지고 간단해졌으며, 특히 $\mathrm{NH}(336.0 \mathrm{~nm}$ 와 337.0 $\mathrm{nm)}$ 분자띠는 현저히 낮아짐을 볼 수 있었다.

\section{2. 플라즈마의 들뜸 온도와 전자밀도 측정}

들뜸 온도는 $\mathrm{Fe}$ 의 스펙트럼을 사용하여 측정하였 다. 이는 $\mathrm{Fe}$ 이 충분한 방출세기를 가지고 있고 전이 확률의 정확한 값을 얻을 수 있으며 들뜸 에너지 범 위가 크기 때문이다. 그리고 사용되는 방출선의 파 장이 $370 \mathrm{~nm} 380 \mathrm{~nm}$ 에 서로 근접 $(371.994 \mathrm{~nm}$, $373.487 \mathrm{~nm}, 373.713 \mathrm{~nm}, 374.826 \mathrm{~nm}, 374.947 \mathrm{~nm}$, $375.824 \mathrm{~nm}$ )해 있어서 파장에 따른 분광기의 보정 이 필요 없고 방출선의 자체흡수가 적다는 특성을 가지고 있기 때문이다. 해당 파장의 신호세기를 스 펙트럼을 통해 측정하여 방출선의 세기를 에너지에 대하여 도시하면 $-1 / \mathrm{kT}$ 에 해당하는 기울기값을 얻 을 수 있고 이를 이용하여 플라즈마의 온도를 구할 수 있다. 전자밀도 $\left(\mathrm{n}_{\mathrm{e}}\right)$ 는 Saha-Eggert 법(세기비법 $)^{29}$ 을 역시 Fe $1000 \mathrm{mg} / \mathrm{L}$ 용액을 사용하여 Fe I (252.285 $\mathrm{nm})$ 와 Fe II $(258.588 \mathrm{~nm})$ 의 원자선과 이온선의 비 를 측정함으로써 구하였다.

사용 범위의 출력에서 측정된 $\operatorname{Tex}($ 들뜸 온도)는 평 균 4,350 K 이었다. 이는 Okamoto 의 He-MIP ${ }^{16}$ 에 비 해 $500 \mathrm{~K}$ 정도가 온도가 낮은 것이며 이는 아직 형성 된 플라즈마가 모든 것이 최적화된 상태는 아니라고 보인다. 플라즈마의 횡적 온도분포를 살펴보기 위하여 스키머의 중심에 직경 $1 \mathrm{~mm}$ 의 구경을 사용하여 온도 측정을 한 결과, 중심에서부터 벽 쪽으로의 온도변화 는 별 차이가 없었다. 출력 변화에 따른 들뜸 온도는 Table 5에서 보는 바와 같이 대체적으로 출력에 따라 온도는 증가하는 것으로 보인다.

Saha-Eggert 법에 의해 측정된 전자밀도는 $3.7 \times 10^{11}$ 
Table 4. Plasma length change with end-plate hole diameter and power (ICP-small tube)

\begin{tabular}{cccccccc}
\hline \hline & \multicolumn{6}{c}{ Plasma length(cm) } \\
\hline \multicolumn{2}{c}{ Power(W) } & 400 & 500 & 600 & 700 & 800 & 900 \\
\hline \multirow{2}{*}{$\mathrm{D}$} & 12.7 & 0.2 & 0.4 & 0.7 & 1.2 & 1.3 & 1.5 \\
$(\mathrm{~mm})$ & 13.3 & 0.4 & 0.7 & 1.0 & 1.5 & 2.0 & 2.5 \\
& 19.0 & 1.3 & 2.0 & 2.5 & 3.5 & 4.0 & \\
\hline
\end{tabular}

Table 5. Excitation temperature change with the power

\begin{tabular}{cccccc}
\hline \hline Power $(\mathrm{W})$ & 500 & 600 & 700 & 800 & 900 \\
\hline $\mathrm{T}(\mathrm{K})$ & 4,140 & 4,240 & 4,390 & 4,500 & 4,430 \\
\hline
\end{tabular}

$/ \mathrm{cm}^{3}$ 이었다. 이 값을 다른 $\mathrm{He} \mathrm{MIP}^{16}$ 와 비교해 보면 $\left(10^{13} / \mathrm{cm}^{3} \sim 10^{14} / \mathrm{cm}^{3}\right.$ 정도) 비교적 낮은 전자밀도 값을 갖고 있는데 이는 본 연구에서 사용되는 고출력 플라 즈마 기체의 흐름량이 커서 플라즈마의 밀도가 낮아 졌기 때문으로 생각된다.

\section{3. 헬륨 플라즈마의 분석적 능력}

헬륨 플라즈마의 분석적 능력을 알아보기 위하여 먼저 출력과 운반기체 유량 변화에 따른 신호의 세기 를 측정하였다. 출력변화에 따른 신호세기는 Fig. 8 에서 보는 바와 같이 출력에 따라 신호세기는 증가한 다. 하지만 $600 \mathrm{~W}$ 이상에서는 오히려 신호가 감소하 는데 그 이유는 높은 출력에서는 더 많은 플라즈마 기체가 요구되고 이에 따라 신호는 감소하는 것으로 보인다. 시료운반 기체의 유량에 따른 신호세기는 Fig. 9와 같이 $0.36 \mathrm{~L} / \mathrm{min}$ 에서 신호세기가 가장 크며 기체흐름이 더 커지면 신호세기가 떨어지는데 이는 운반기체의 흐름속도가 너무 빠르면 에어로졸이 플라 즈마와 충분히 접촉하지 못하기 때문으로 생각된다.

$\mathrm{KCl} 1000 \mathrm{mg} / \mathrm{L}$ 을 사용하여 $\mathrm{Cl}$ 원소의 이온선인

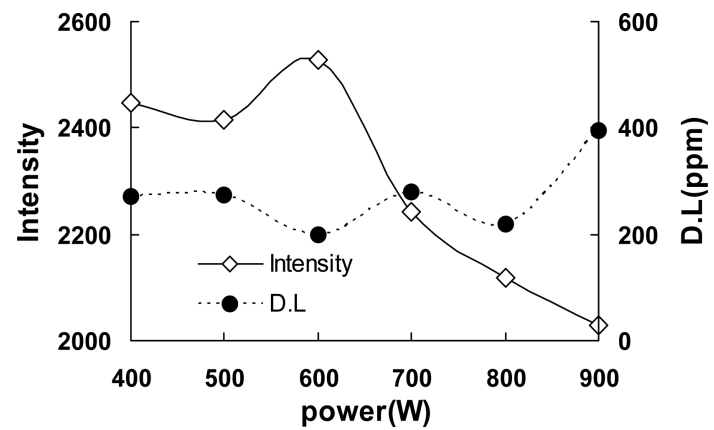

Fig. 8. Change of signal and detection limit with power for $\mathrm{Cl}(\mathrm{II})$.

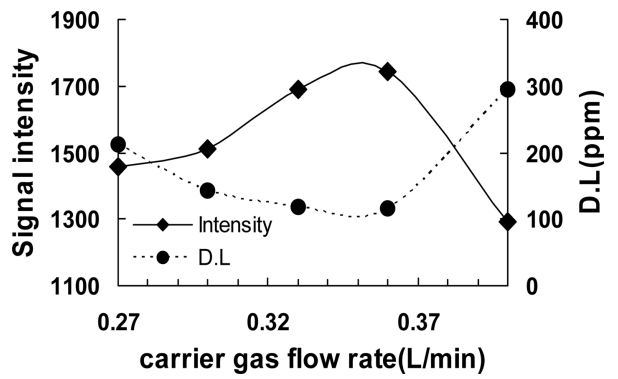

Fig. 9. Change of signal and detection limit with carrier gas flow rate for $\mathrm{Cl}(\mathrm{II})$.

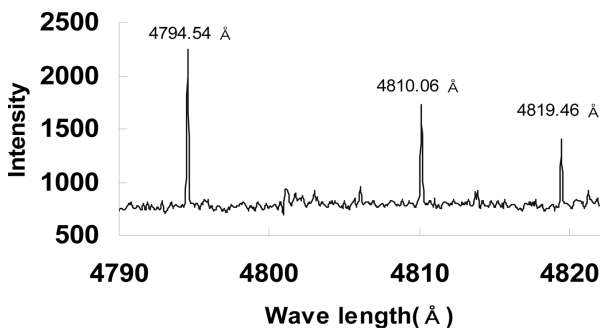

Fig. 10. Characteristic of three $\mathrm{Cl}$ lines in $\mathrm{He}$ microwave plasma.

$479.454 \mathrm{~nm}, 481.006 \mathrm{~nm}, 481.946 \mathrm{~nm}$ 을 측정하였다 (Fig. 10). 세기의 비는 각각 $1.6: 1.2: 1$ 로 측정되었고 이에 가장 신호가 큰 $\mathrm{Cl} \mathrm{II}(479.454 \mathrm{~nm})$ 을 선택하여 검출한계를 구해 보았다. 염소의 경우, 검출한계는 약 $116 \mathrm{mg} / \mathrm{L}$ 정도로서 아직 만족할 만한 결과를 보여주 고 있지 못하다. 이는 아직 $\mathrm{He}$ 마이크로파 플라즈마 가 안정화 되어 있지 않으며 현재까지의 연구는 고출 력 플라즈마의 생성에 주력하였기 때문이다. 고출력 헬륨 플라즈마는 무엇보다 수용액시료를 직접 분무하 여 분석할 수 있고 들뜸 온도와 전자밀도의 측정으로 보아 분석적 사용 가능성을 충분히 보여주고 있다.

\section{4. 결 론}

WR-340 도파관을 이용해 여러 기체에 대하여 1 $\mathrm{kW}$ 급 고출력 플라즈마를 형성시킬 수 있었다. Cavity 의 여러 변수를 최적화 시켜 헬륨, 질소, 아르곤 마이 크로파 플라즈마를 얻었고 특히 헬륨 플라즈마는 가 장 좋은 안정성을 보였다. 질소는 도넛형 플라즈마로 수용액 시료를 직접 도입 분석할 수 있는 플라즈마의 형태가 형성되므로 좋은 연구대상이 될 것으로 보인 다. 아르곤은 쉽게 점화되며 플라즈마를 형성하나 아 직은 안정된 도넛 형태를 만들지 못하고 실 형태로 외곽에 얇게 형성이 되므로 분석용으로 이용을 할 수 
없지만 추후에 더 연구할 필요성이 있는 것으로 생각 된다.

고출력 $\mathrm{kW}$ 급 헬륨 플라즈마는 도넛형태가 아닌 실 린더 형태로서 출력이 높아짐에 따라 다량의 냉각기 체 $(25 \mathrm{~L} / \mathrm{min} 30 \mathrm{~L} / \mathrm{min})$ 가 요구된다. 자체 제작한 세라 믹지지체를 넣은 토치를 개발하여 사용하였으나 개선 점을 보여주지 못하며 더 깊은 연구가 필요하다. 바탕 의 분자띠를 제거하기 위하여 extend torch를 사용하 여 스펙트럼을 관찰한 결과 공기와의 접촉에 의해 형 성되는 $340 \mathrm{~nm}$ 영역에서 나타나는 $\mathrm{NH}$ 의 분자띠의 대 부분을 제거할 수 있었다.

플라즈마의 들뜸 온도는 $4350 \mathrm{~K}$, 전자밀도는 $1.5 \times 10^{11} / \mathrm{cm}^{3}$ 으로 Okamoto의 플라즈마와 비교할 때, 온도와 전자밀도가 모두 낮았다. 염소의 검출한계는 $116 \mathrm{mg} / \mathrm{L}$ 정도의 수준으로 아직도 많은 개선점이 요 구되고 있으나 현재까지 본 연구에서는 일차적인 개 발에 집중하였고 연속적인 분석활용에 대한 연구가 연 구실에서 진행될 예정이다. 효율적인 플라즈마 기체의 흐름에 대한 개선의 연구가 이루어지면 고출력 헬륨 마이크로파 플라즈마의 감도와 분석능력의 향상으로 실제적인 분석응용이 잘 이루어 질 것으로 기대된다.

\section{참고문헌}

1. C. I. M. Beenakker, B. Bosman and P. W. J. M. Boumans, Spectrochim. Acta, 33B, 373-381 (1978).

2. K. G. Michlewicz and J. W. Carnahan, Anal. Chem., 57, 1092-1095 (1985).

3. R. D. Deutsch and G. M. Hieftje, Appl. Spectrosc., 39, 214-222 (1985).

4. M. Moisan, C. Beaudry and P. Leprince, IEEE transactions on Plasma Science, PS-3, 55-59 (1975).

5. M. Moisan, R. Pantel, J. Hubert, E. Bloyet, P. Leprince, J. Marec and A. Ricard, J. Microwave Power, 14, 57-61 (1979).

6. Q. Jin, C. Zhu, M. W. Borer and G. M. Hieftje, Spectrochim. Acta., 46B, 417-430 (1991).

7. Q. Jin, H. Zhang, J. Anal. At. Spectrom., 9, 851-856 (1994).

8. A. Besner and J. Hubert, Appl. Spectrosc., 52, 894-899 (1998).

9. D. Boudreau and J. Hubert, Appl. Spectrosc., 47, 609-
614 (1993).

10. B. M. Spencer, B. W. Smith and J. D. Winefordner, Appl. Spectrosc., 48, 289-296 (1994).

11. B. M. Spencer, A. R. Raghani, and J. D. Winefordner, Appl. Spectrosc., 48, 643-646 (1994).

12. A. R. Hoskinson, J. Hopwood, N. W. Bostrom, J. A. Crank and C. Harrison, J. Anal. At. Spectrom., 26, 1258-65 (2011).

13. K. Jankowski, A. Ramsza, E. Reszke and M. Strzelec, J. Anal. At. Spectrom., 25, 44-47 (2010).

14. A. Tyburska and K. Jankowski, Analytical Methods, 3, 659-663 (2011).

15. K. Jankowski, A. Jacowska, A. P. Ramsza and E. Reszke, J. Anal. At. Spectrom., 23, 1234-40 (2008).

16. Y. Okamoto, Jpn. J. Appl. Phys., 38, L338-L341 (1999).

17. Y. Okamoto, M. Yasuda and S. Murayama, Jpn. J. Appl. Phys., 29, 670-672 (1990).

18. H. Yamada and Y. Okamoto, Appl. Spectrosc., 55, 114118 (2001).

19. M. Ohata and N. Furuta, J. Anal. At. Spectrom., 12, 341-347 (1997).

20. K. Ogura, H. Yamada, Y. Sato, and Y. Okamoto, Appl. Spectrosc., 51, 1496-1499 (1997).

21. A. Matsumoto, A. Oheda and T. Nakahara, Anal. Sci., 17, 963-966. (2001).

22. Y. Okamoto, H. Murohashi and S. Wake, Anal. Sci., 17, 967-970. (2001).

23. Z. Zhang and K. Wagatsuma, J. Anal. At. Spectrom., 17, 699-703 (2002).

24. T. Maeda and K. Wagatsuma, Spectrochim. Acta., 60B, 81-87 (2005).

25. K. B. Cull and J. W. Carnahan, Appl. Spectrosc., 42, 1061-1065 (1988).

26. Mingin Wu and J. W. Carnahan, Appl. Spectrosc., 46, 163-168 (1992).

27. S. K. Chan, R. L. Van Hoven and A. Montaser, Anal. Chem., 58, 2342-2343 (1986).

28. M. T. C. De Loos-Vollerbregt, J. J. Tiggelman and L. De Galan, Spectrochim. Acta., 43B, 773-781 (1988).

29. D. J. Kalnicky, V. A. Fassel and R. N. Kniseley, Appl. Spectrosc., 31, 137-151 (1977). 